\title{
FAIR VALUATION OF VARIOUS PARTICIPATION SCHEMES \\ IN LIFE INSURANCE
}

\author{
BY
}

Pierre Devolder and InMaculada Domínguez-Fabián

\begin{abstract}
Fair valuation is becoming a major concern for actuaries, especially in the perspective of IAS norms. One of the key aspects in this context is the simultaneous analysis of assets and liabilities in any sound actuarial valuation. The aim of this paper is to illustrate these concepts, by comparing three common ways of giving bonus in life insurance with profit: reversionary, cash or terminal. For each participation scheme, we compute the fair value of the contract taking into account liability parameters (guaranteed interest rate and participation level) as well as asset parameters (market conditions and investment strategy). We find some equilibrium conditions between all those coefficients and compare, from an analytical and numerical point of view, the systems of bonus. Developments are made first in the classical binomial model and then extended in a Black and Scholes economy.
\end{abstract}

\section{KEYWORDS}

Fair value, participation scheme, asset and liability management

\section{INTRODUCTION}

If for a long time life insurance could have been considered as a "sleeping beauty", things have changed dramatically as well from a theoretical point of view as from industrial concerns. Nowadays, the financial risks involved in life insurance products are surely amongst the most important challenges for actuaries. The need to update our actuarial background taking into account the real financial world has been recently emphasized by Hans Bühlman in a recent editorial in ASTIN BULLETIN (Bühlman (2002)). The classical way of handling financial revenues in life insurance was characterized by two assumptions: stationarity of the market (no term structure of interest rate) and absence of uncertainty (deterministic approach); all this leading to the famous actuarial paradigm of the technical guaranteed rate: all the future was summarized in one magic number. Clearly things are not so simple and life insurance is a perfect example of stochastic process (even more than non life); the two dimensions of time and 
not in equilibrium. Indeed using respectively formulas (49) and (50), the fair values can be written as follows:

- in the reversionary case:

$$
\begin{aligned}
& \overline{F V}_{0}^{T}(v)={ }_{T} p_{x} \frac{1}{(1+r)^{T}}\left(1+i+B K^{*}\right)^{T} \\
& \text { with: } K^{*}=(1+r) c(i, \gamma, 1)
\end{aligned}
$$

- in the cash case :

$$
\overline{F V}_{0}^{T}(v)={ }_{T} p_{x}\left(\left(\frac{1+i}{1+r}\right)^{T}+B_{C} K^{*} \frac{1}{(1+r)^{T}} \frac{(1+r)^{T}-(1+i)^{T}}{(r-i)}\right)
$$

which have exactly the same form as in the binomial case. So the same conclusion can be drawn.

\section{CONCLUSION}

In this paper, we have developed various formulations in order to compare the fair value for life insurance products based on three participation schemes: reversionary, cash and terminal bonus, taking into account simultaneously the asset side and the liability side in a multiple period model.

We have shown that the fair value depends on the investment strategy (and on the associated risk), on the participation level and on the guaranteed rate but also on the bonus system chosen. We have found some explicit equilibrium conditions between all these parameters.

A deep comparison has been made between the three participation schemes, as well in terms of computation of the fair value as in the equilibrium conditions. Using first a binomial model, we have obtained closed forms and given clear interpretations on the link between the market conditions, the volatility of the assets and the parameters of the product. A same approach, leading to similar conclusions, has been proposed in a time continuous model. The model could be also extended in order to take into account other aspects like surrender options, periodical premiums or the longevity risk.

\section{REFERENCES}

Aase, K.K. and Persson, S.A. (1994) Pricing of unit-linked life insurance policies, Scandinavian Actuarial Journal, 1, 26-52.

BACINELLO, A.R. (2001) Fair pricing of Life Insurance participating policies with a minimum interest rate guaranteed, ASTIN Bulletin, 31(2), 275-298.

BACINELlo, A.R. (2003a) Fair valuation of a guaranteed life insurance participating contract embedding a surrender option, Journal of Risk and Insurance, 70(3), 461-487.

BACINELlo, A.R. (2003b) Pricing guaranteed life insurance participating policies with annual premiums and surrender option, North American Actuarial Journal, 7(3), 1-17.

BRIYS, E. and DE VARENNE, F. (1997) On the risk of insurance liabilities: debunking some common pitfalls, Journal of Risk an Insurance, 64(4), 673-694. 
Bühlman, H. (2002) New Math for Life Actuaries, ASTIN Bulletin, 32(2), 209-211.

BrenNan, M.J. and SChwartZ, E.S. (1976) The pricing of equity linked life insurance policies with an asset value guarantee, Journal of Financial Economics, 3, 195-213.

Cox, J., Ross, S. and Rubinstein, M. (1979) Option Pricing: a simplified approach, Journal of Financial Economics, 7, 229-263.

Delbaen, F. (1986) Equity linked policies, BARAB, 80, 33-52.

Devolder, P. and Domínguez-FABIÁn, I. (2004) Deflators, actuarial discounting and fair value, Finance, 25, 49-69.

Grosen, A. and Jorgensen, P.L. (2000) Fair valuation of life insurance liabilities: the impact of interest rate guarantees, surrender options and bonus policies, Insurance: Mathematics and Economics, 26(1), 37-57.

Haberman, S., Ballotta, L. and Wang, N. (2003) Modelling and valuation of guarantees in with-profit and unitised with profit life insurance contracts, $7^{\text {th }}$ Insurance: Mathematics and Economics congress, Lyon.

HAnsen, M. and Miltersen, K.R. (2002) Minimum rate of return guarantees: the Danish case, Scandinavian Actuarial Journal, 4(4), 280-318.

HARDY, M. (2003) Investement guarantees: modelling and risk management for equity-linked insurance, John Wiley \& Sons.

Moller, T. (1998) Risk minimizing hedging strategies for unit-linked life insurance contracts, Astin Bulletin, 28, 17-47.

Nielsen, J.A. and Sandmann, K. (1995) Equity-linked life insurance: a model with stochastic interets rates, Insurance: Mathematics and Economics, 16, 225-253.

Norberg, R. (2002) Life Insurance Mathematics 2002, $6^{\text {th }}$ Insurance: Mathematics and Economics congress, Lisbon.

Pierre Devolder

Institut des Sciences Actuarielles

Université Catholique de Louvain

6 , rue des Wallons,

1348 Louvain-la-Neuve,

Belgium

E-mail:devolder@fin.ucl.ac.be

INMACULADA DoMínGUEZ-FABIÁN

Department of Financial Economy,

University of Extremadura,

Spain

E-mail: idomingu@guadiana.unex.es 